\title{
First open access ensemble climate envelope predictions of Assamese macaque Macaca assamensis in Asia: a new role model and assessment of endangered species
}

\author{
Ganga Ram Regmi ${ }^{1}$, Falk Huettmann ${ }^{2, *}$, Madan Krishna Suwal, ${ }^{1,3}$, Vincent Nijman ${ }^{4}$, \\ K. A. I. Nekaris ${ }^{4}$, Kamal Kandel ${ }^{1}$, Narayan Sharma ${ }^{5,6}{ }^{\text {, Camille Coudrat }}{ }^{4}$ \\ ${ }^{1}$ Global Primate Network-Nepal, GPO Box 26288, Kathmandu, Nepal \\ ${ }^{2}$ EWHALE lab, Institute of Arctic Biology, Biology and Wildlife Department, University of Alaska Fairbanks (UAF), \\ Fairbanks, Alaska 99775, USA \\ ${ }^{3}$ Department of Geography, University of Bergen, Fosswinckelsgt 6, PB 7802, 5020 Bergen, Norway \\ ${ }^{4}$ Oxford Brookes University, Oxford, OX3 0BP, UK \\ ${ }^{5}$ Department of Environmental Biology and Wildlife Sciences, Cotton College State University, Pan Bazar, Guwahati 781001, \\ Assam, India \\ ${ }^{6}$ School of Natural Sciences and Engineering, National Institute of Advanced Studies, Indian Institute of Science Campus, \\ Bengaluru 560012, Karnataka, India
}

\begin{abstract}
Species distribution models are a key component for understanding a species' potential occurrence, specifically in vastly undersampled landscapes. The current species distribution data for the Assamese macaque Macaca assamensis are outdated, but suggest a patchy distribution in moist broadleaved forests in South and Southeast Asia. Therefore, in this study, we used a species distribution model to explore the potential climatic niche of this species and assess its distribution and potential barriers in 12 South and Southeast Asian countries. We combined primary and secondary species occurrence records from different countries. We applied Classification and Regression Tree (CART), TreeNet (boosting), RandomForest (bagging) and Maximum Entropy (MaxEnt) machine-learning algorithms with elevation as well as 19 bioclimatic variables for the first ensemble predictions ever completed for this species. Our results suggested that the predicted distribution of the Assamese macaque is strongly associated with precipitation of warmest quarter (BIO18), temperature annual range (BIO7) and temperature seasonality (BIO4). Our prediction shows a continuous potential climatic niche of the species from east of the Kaligandaki River in Nepal to Lao People's Democratic Republic. There are also potential niche patches in Bhutan, Southeast China, Thailand and Cambodia, while Pakistan and Afghanistan have no potential niche for the species. We believe that our workflow presents a new conservationoriented open access research template to progress empirical primate conservation worldwide.
\end{abstract}

KEY WORDS: Assamese macaque - Potential distribution niche - Machine learning . Ensemble model prediction · Open access data

\section{INTRODUCTION}

In addition to basic knowledge about diversity and life history, conservation of the world's primates requires data on many more basic metrics, including

${ }^{*}$ Corresponding author: fhuettmann@alaska.edu distribution (Cushman \& Huettmann 2010, Drew et al. 2011). However, there are many elusive species and it is often difficult to obtain information on the characteristics of their distribution, such as geography and habitat requirements. Ecological niche restricted. Authors and original publication must be credited. 
modeling techniques - often referred to as species distribution models (SDMs) (Guisan et al. 2006) - are used to quantify and map the distribution of elusive species on a large spatial scale using known occurrence records (Huettmann \& Diamond 2001, Guisan et al. 2006). SDMs aid rapid assessment and can be used as a quantification tool for estimating the predicted range and potential distribution of and barriers to the species occurrences in areas not previously surveyed (Thorn et al. 2009), which may be difficult to access (see Kandel et al. 2015 for an example). Wildlife management is often based on the information embodied in maps generated using SDMs. Such maps may also help to identify barriers and provide predicted population estimates in space and time (Drew et al. 2011). Even when 'just' based on climate envelopes, they provide a baseline for predicting a species' response to human-induced threats and impacts, such as landscape alterations and climate change, and for the identification and prioritization of key conservation sites (Thorn et al. 2009, Vidal-García \& Serio-Silva 2011).

This study aimed to assess the distribution of the Assamese macaque Macaca assamensis (taxonomic serial number TSN 573018; see Supplement 1 at www.int-res.com/articles/suppl/n036p149_supp.pdf for more taxonomic details) using the latest research methods and data. This is important because the IUCN has already classified the Assamese macaque as a Near Threatened species (Boonratana et al. 2008). The limited empirical data available suggest that this species is patchily distributed in South and Southeast Asian countries (Wada 2005). However, a coherent, empirical and useful distribution map across its range is still unavailable, and barriers are not well described or explained on a landscape level. So far, this species has been reported from the lower and middle ranges of the Himalayas reaching from central Nepal eastward through Bhutan, northeastern India, northern and eastern Myanmar, southern China, northern and western Thailand, Lao People's Democratic Republic (PDR) and northern Vietnam. While the species is recorded between 500 and $3500 \mathrm{~m}$ above sea level, an isolated record is available from the Sundarbans coastal swamps of southwestern Bangladesh (Fooden 1982).

The lack of meaningful and available distribution data, or in lieu, ecological niche models and computationally intense data-mining methods, prevents us from addressing conservation management questions with high and modern rigor. This is an almost global situation for behavior-dominated animal research (Jochum \& Huettmann 2010; but see Yang et al. 2015 for an application), which hampers effective conservation management for those species, while climate change progresses and habitats decay further. It is inherently clear that the Assamese macaque and conservation management must be seen in a wider and more global landscape context using the best-available tools possible. Furthermore, a better and more relevant understanding of this taxon is needed given the massive habitat changes in Asian countries (Huettmann 2012 and related chapters within). We believe that the provision of a quantitative distribution formula and use of the latest computational tools and GIS data would help primatologists, biogeographers, evolutionary biologists and conservation managers to identify geographically suitable habitat areas for this species for the first time; this should be done in a consistent fashion using the latest open access data and global assessment tools, which are essential for anyone interested in such questions (sensu Nemitz et al. 2012, Kandel et al. 2015). Although this study is designed at the macro level, we posit that it can further our understanding of the historic macaque evolutionary pattern and that it can help in minimizing anthropogenic pressure on the species' predicted potential habitat.

\section{MATERIALS AND METHODS}

\section{Study area}

Our study area consists of landscapes from 12 Asian nations: Afghanistan, Pakistan, China, Nepal, India, Bhutan, Bangladesh, Myanmar, Thailand, Vietnam, Lao PDR and Cambodia (Fig. 1). Of these, the first eight are part of Hindu-Kush Himalaya (HKH see www.icimod.org for details); the others are inherently connected to $\mathrm{HKH}$ through climate, watersheds and culture.

\section{Study species}

The Assamese macaque Macaca assamensis inhabits the foothills of the Central and Eastern Himalayas and the adjoining mountain chains of South and Southeast Asia (Fooden 1980, 1982, Molur et al. 2002, Boonratana et al. 2008). Fooden (1982) reported for this species that forest type (e.g. broadleaf evergreen forests) rather than the temperature per se determines the distribution of Assamese macaque. For more details on this species see also the IUCN (www.iucnredlist.org/details/12549/0) and associated 


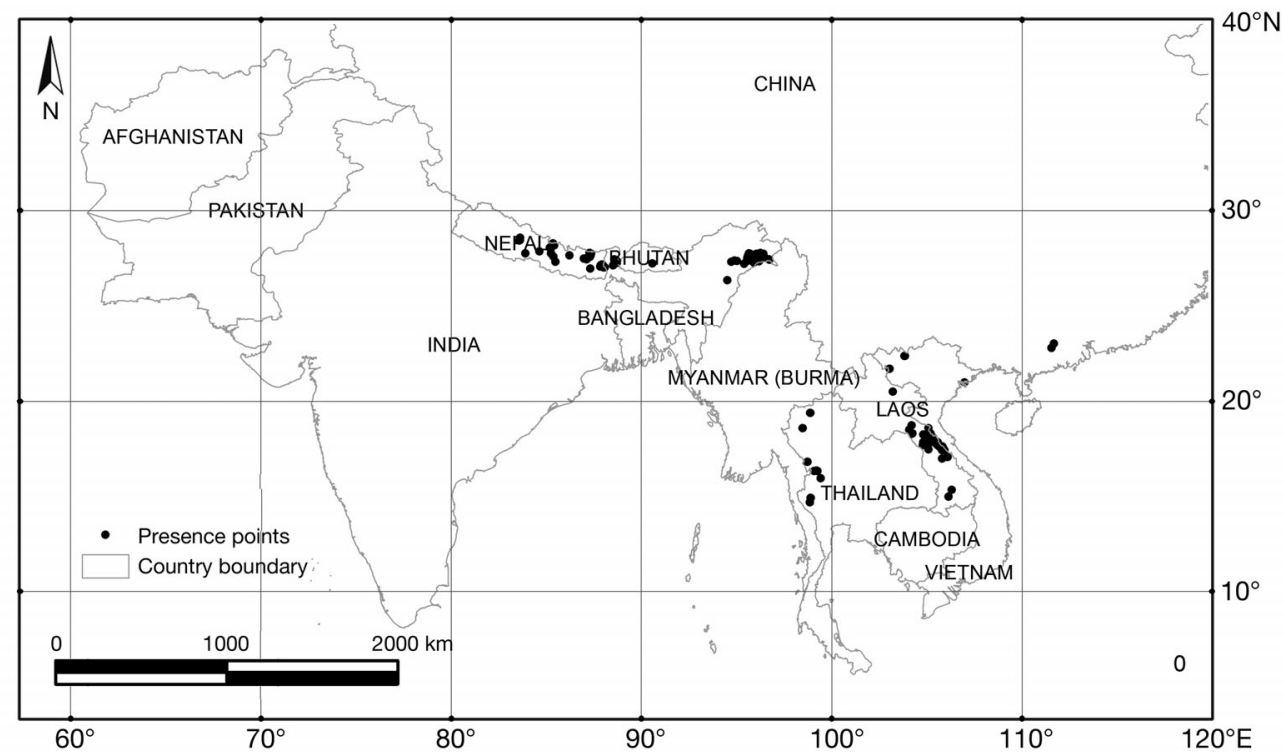

Fig. 1. Study area map with occurrence points for Assamese macaque. The map also depicts the countries in the study area

information, e.g. the Integrated Taxonomic Information System (ITIS; www.itis.gov/servlet/SingleRpt/Single Rpt?search_topic=TSN\&search_value=573018\#null).

The species - along with $M$. sinica, $M$. radiata, $M$. thibetana, M. munzala (Sinha et al. 2005) and the recently discovered M. leucogenys (Li et al. 2015) - is assigned to the sinica group of macaques. This is a wider species group that is defined by shared and derived characters of male and female reproductive anatomy (Fooden 1980, 1982), phylogenetic relationship and evolutionary legacy (Chakraborty et al. 2007). There are 2 clearly recognized subspecies of $M$. assamensis on the basis of relative tail length in adult males: the Southeast Asian M. assamensis assamensis (TSN 945194, commonly known as the eastern Assamese macaque) has a shorter tail in relation to the sub-Himalayan M. assamensis pelops (TSN 945195, commonly known as western Assamese macaque; see Supplement 1 for more taxonomic species details). The Brahmaputra River of northeastern India is the zoogeographical barrier separating these 2 subspecies (Fooden 1982). Assamese macaques live sympatrically with congeneric macaques i.e. M. mulatta, $M$. thibetana, M. munzala, M. leonina, M. arctoides and possibly with the newly discovered $M$. leucogenys in Southeast China; in many areas, 3 or 4 macaque species inhabit the same forest (Sharma et al. 2012).

\section{Collating 'presence-only' data of Assamese macaque}

Our methods are outlined as a workflow in Fig. 2. We compiled our own field survey (primary) pres- ence locations as well as published (secondary) occurrences of the species that were accessible to us. All relevant data are given in Supplement 2 (see www.intres.com/articles/suppl/n036p149_supp2+4.zip) and are publicly available there. First, we collected the data from our own fieldwork in Nepal (2005-2013), India (2009-2012) and Lao PDR (2011-2013). Second, we compiled occurrence data for Assamese macaque from the Global Biodiversity Information Facility website (www.gbif.org). GBIF had 17 occurrence records we could use, all of which came from museum records. Third, a few presence locations were provided by researchers who had previously conducted primate surveys in Nepal, India, Thailand and Vietnam within the Assamese macaque range. Finally, we extracted some presence locations of this species from known locations and from various published sources (Chalise \& Ghimire 1998, Chalise 1999, Molur et al. 2002, Wada 2005, Regmi \& Kandel 2008). All data are confirmed presences, and data can be viewed in detail by any investigators interested; we have made these data publicly available with ISOcompliant metadata in the public domain via dSPACE of the library of the University of Alaska Fairbanks (UAF). This work resulted in a total of 296 'presenceonly' locations of Assamese macaque (Fig. 1).

\section{Predictors used for climate envelope modeling}

As outlined in Breiman (2001) and Drew et al. (2011), our models are correlative and predictive; therefore, we employed many environmental proxies 


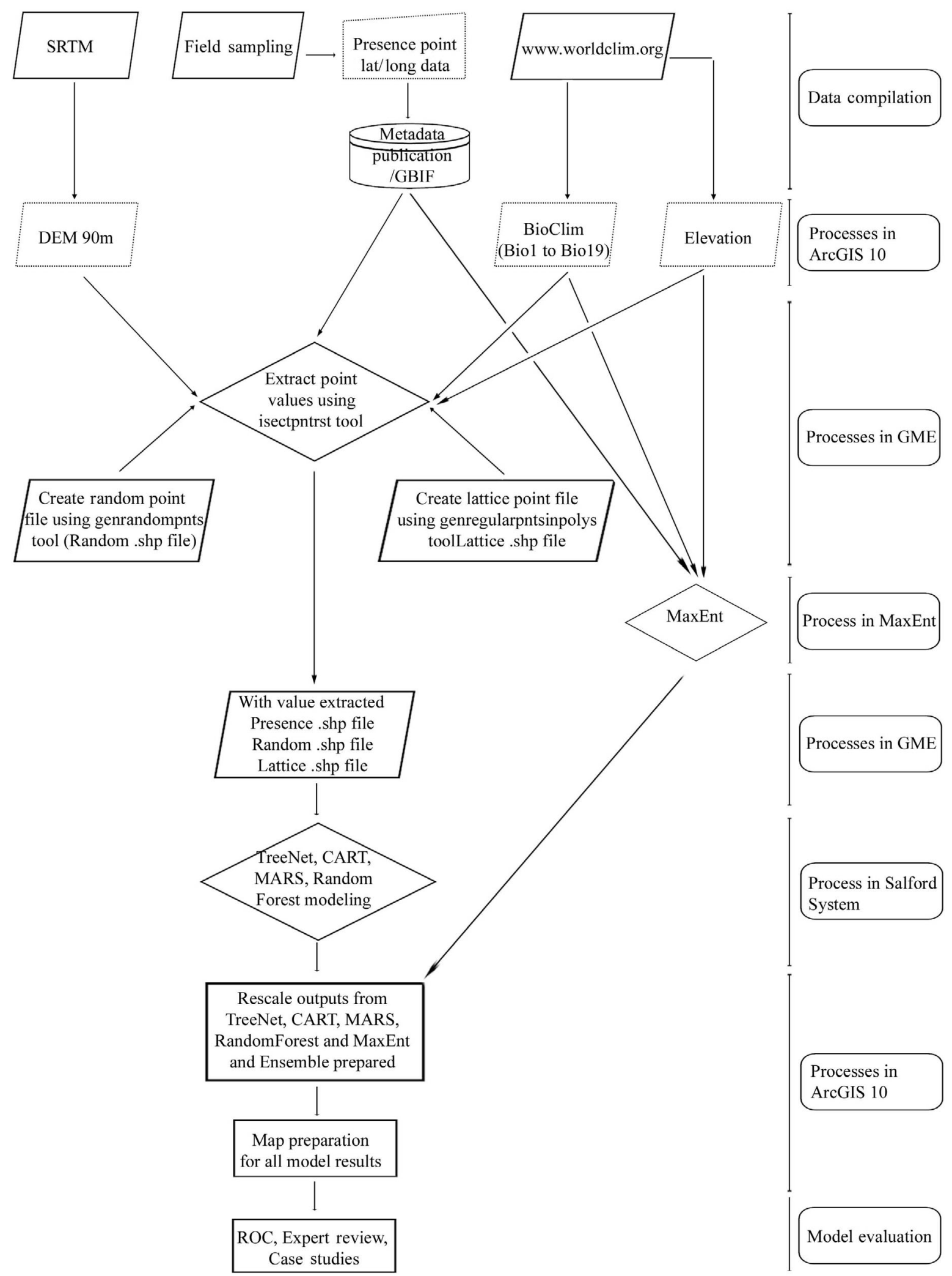

Fig. 2. Flowchart of open access and open source model methods used in this study to assess and obtain the first and best-possible model predictions for Assamese macaque. For abbreviations see 'Materials and methods' 
in our machine-learning algorithms. We used 20 different predictor variables (see Table 1 for details) to estimate the ecological niche. These variables included temperature and precipitation as well as their derivatives and elevation data. We used open access data for 19 bioclimatic variables from WorldClim (www.worldclim.org). These data are well described by Hijmans et al. (2005). The $90 \mathrm{~m}$ Shuttle Radar Topography Mission digital elevation model (DEM) is described in detail by US Geological Survey (http://gdex.cr.usgs.gov/gdex/; see Herrick et al. 2013 and Kandel et al. 2015). Because we rely on tree-based models, which are non-parametric, there is no relevant need to deal with correlation issues in the dataset per se.

\section{Modeling process}

Our data input and models are open access (Supplement 2 and www.worldclim.org). We generally followed Breiman (2001) to extract major signals from the data and for inference from predictions. Our model methods are robust when using opportunistic data locations; see also Coudrat \& Nekaris (2013), Kandel et al. (2015) and Moyes et al. (2016) for similar applications. Before preparing the model, we first prepared a dataset including pseudo-absence (random) points and lattice points within the study area using the Geospatial Modelling Environment (GME) software (www.spatialecology.com/gme/). The random points were generated with a minimum distance of $800 \mathrm{~m}$ ( $\mathrm{n}=140280$ point locations), and a lattice points grid (total 154 810) file was created with regular spaced points with a neighboring distance of $10 \mathrm{~km}$. The specific spacings (random and lattice) were made to obtain a more representative and equally distributed sample size for the vast study area. Then the values from all 20 predictor variables were extracted to presence, random and lattice points using GME software. The random points were combined with the presence points into one binomial data table and analyzed further.

We used 2 different platforms for data mining and predictive modeling, namely, SPM7 by Salford Systems (www.salford-systems.com/en/; see Popp et al. 2007 for an example) and MaxEnt (Phillips et al. 2006). In SPM7, we used 3 different algorithms, namely, Classification and Regression Tree (CART), TreeNet ( $\mathrm{TN}$; boosting) and RandomForest (RF; bagging). We employed their default settings because we know these tend to perform the best for data problems such as those faced here. From all
Table 1. List and description of predictor variables. DEM: digital elevation model

\begin{tabular}{|c|c|}
\hline Name & Variable description \\
\hline BIO1 & Annual mean temperature \\
\hline $\mathrm{BIO} 2$ & $\begin{array}{l}\text { Mean diurnal range (mean of monthly } \\
(\max \text { temp - min temp)) }\end{array}$ \\
\hline BIO3 & Isothermality (BIO2/BIO7) $(\times 100)$ \\
\hline $\mathrm{BIO} 4$ & $\begin{array}{l}\text { Temperature seasonality (standard } \\
\text { deviation } \times 100 \text { ) }\end{array}$ \\
\hline BIO5 & Max temperature of warmest month \\
\hline $\mathrm{BIO} 6$ & Min temperature of coldest month \\
\hline $\mathrm{BIO} 7$ & Temperature annual range (BIO5 - BIO6) \\
\hline BIO8 & Mean temperature of wettest quarter \\
\hline BIO9 & Mean temperature of driest quarter \\
\hline BIO10 & Mean temperature of warmest quarter \\
\hline BIO11 & Mean temperature of coldest quarter \\
\hline $\mathrm{BIO} 12$ & Annual precipitation \\
\hline BIO13 & Precipitation of wettest month \\
\hline $\mathrm{BIO} 14$ & Precipitation of driest month \\
\hline $\mathrm{BIO} 15$ & $\begin{array}{l}\text { Precipitation seasonality (coefficient of } \\
\text { variation) }\end{array}$ \\
\hline BIO16 & Precipitation of wettest quarter \\
\hline BIO17 & Precipitation of driest quarter \\
\hline BIO18 & Precipitation of warmest quarter \\
\hline BIO19 & Precipitation of coldest quarter \\
\hline DEM & $\begin{array}{l}\text { Shuttle Radar Topography Mission (SRTM) } \\
90 \mathrm{~m} \text { and WorldClim }(\sim 30 \text { arc second })^{\mathrm{a}}\end{array}$ \\
\hline$I$ & lim DEM was only used in MaxEnt \\
\hline
\end{tabular}

these algorithms, we made predictions (relative index of occurrence (RIO)) on the lattice points from the presence-random data model.

Maximum Entropy (MaxEnt; Phillips et al. 2006) was run with default settings and logistic output, and the result obtained in ASCII format was converted to a raster format in ArcGIS 10 (ESRI). The raster RIO value for each point in the lattice was then extracted in GME again. This allowed us to compare predicted results from all algorithms.

The actual RIO value ranges of the different models were not numerically consistent; therefore, to make a better comparison, the RIO values of all the algorithms were rescaled from a 0 (less suitable) to 1 (suitable) range. Then we prepared an ensemble RIO by taking the mean of the rescaled RIOs from all 4 models. In many cases, the RIO continuous maps can make it difficult to decide whether an area is suitable or not (thresholding problem). Hence, we decided to prepare a binary (suitable or unsuitable) map using a threshold. We used expert knowledge to determine the threshold. The list of 6 internal and 3 external macaque experts is given in Supplement 3 . We prepared maps of every RIO 0 to 1 value at 0.1 intervals (e.g. $0,0.1,0.2, \ldots 0.9$ and 
1.0) to evaluate the expert cut-off value for each model. These maps were evaluated by different experts (internal and external; see Supplement 3 for details) in the distribution and ecology of the species. Based on the expert-suggested threshold RIO values, geographically suitable area maps for Assamese macaque presence or absence were prepared and further assessed for validity.

\section{RESULTS}

\section{Model selection}

All models in the ensemble showed high area under the curve (AUC) metrics (Table 2). Nearly all their AUC metrics were over 0.95. This is sufficient
Table 2. Area under curve (AUC) and kappa values of the contributing models. Note that these models are binomial, presence and random. Models were run in default mode with 'balanced' setting

\begin{tabular}{|lcc|}
\hline Model name & AUC value & Kappa value \\
\hline CART & 0.97 & 0.064 \\
TreeNet & 0.99 & 0.235 \\
RandomForest & 0.99 & 0.326 \\
MaxEnt & 0.99 & 0.078 \\
Ensemble & 0.99 & 0.105 \\
\hline
\end{tabular}

for rapid assessment studies and our large scale, allowing for robust inference (sensu Breiman 2001). The resulting map is shown in Fig. 3. However, using pseudo-absences and AUC within the model algo-



Fig. 3. Ensemble model prediction (relative index of occurrence, RIO) maps showing the geographically suitable areas for Assamese macaque

Table 3. Variable importance for top 5 predictors of the contributing ensemble models

\begin{tabular}{|lccrrr|}
\hline Model name & $\begin{array}{c}\text { Number 1 } \\
\text { predictor } \\
\text { (importance, \%) }\end{array}$ & $\begin{array}{c}\text { Number 2 } \\
\text { predictor } \\
\text { (importance, \%) }\end{array}$ & $\begin{array}{c}\text { Number 3 } \\
\text { predictor } \\
\text { (importance, \%) }\end{array}$ & $\begin{array}{c}\text { Number 4 } \\
\text { predictor } \\
\text { (importance, \%) }\end{array}$ & $\begin{array}{c}\text { Number 5 } \\
\text { predictor } \\
\text { (importance, \%) }\end{array}$ \\
\hline CART & BIO18 (100) & BIO7 (99) & BIO4 (96) & BIO12 (83) & BIO13 (83) \\
TreeNet & BIO18 (100) & BIO7 (75) & BIO4 (43) & Elevation (27) & BIO6 (26) \\
RandomForest & BIO4 (100) & BIO6 (77) & BIO11 (75) & BIO7 (57) & BIO16 (57) \\
MaxEnt & BIO18 (52.7) & BIO7 (19.5) & BIO4 (7.9) & BIO13 (7.2) & Elevation (6.6) \\
\hline
\end{tabular}


rithm (e.g. subsampled training data) will likely result in somewhat inflated metrics. Other model assessments, such as expert opinion and model prediction tests, are meant to be used, for instance, in areas of known absences.

\section{Variable importance}

Tables $3 \& 4$ show a summary of the predictors and their ranking, according to the model algorithms in the ensemble. We find that predictors BIO4 (temperature seasonality), BIO7 (temperature annual range), BIO18 (precipitation of warmest quarter), elevation and BIO6 (mean temperature of coldest month) are the top 5 predictors for Assamese macaque. A 2dimensional plot of the 2 top predictor combinations can be seen in Fig. 4, exemplifying where this species occurs in the 2-dimensional predictor niche space (Fig. 5 shows that the TreeNet model is optimized and stable).
Table 4. Summary from Table 3 for the top 5 predictors of the contributing ensemble models

\begin{tabular}{|lccc|}
\hline Predictor & $\begin{array}{c}\text { Selection } \\
\text { frequency }\end{array}$ & $\begin{array}{c}\text { Mean position } \\
\text { rank in top 5 } \\
\text { predictors }\end{array}$ & $\begin{array}{c}\text { Mean importance } \\
\text { in the models } \\
\text { selected (\%) }\end{array}$ \\
\hline BIO4 & 3 & 2.3 & 80 \\
BIO7 & 3 & 2.6 & 77 \\
BIO18 & 2 & 1.0 & 100 \\
Elevation & 2 & 2.5 & 64 \\
BIO6 & 2 & 3.5 & 53 \\
\hline
\end{tabular}

\section{Partial dependence plots}

The individual partial dependence plots in Figs. 6 to 10 show how Assamese macaques link functionally with the identified top 5 predictors. These can be generalized and interpreted approximately as resource selection functions (RSFs) (Manly et al. 2002). The $y$-axis shows the RIO (presence or random) and the $X$-axes show the specific predictors.
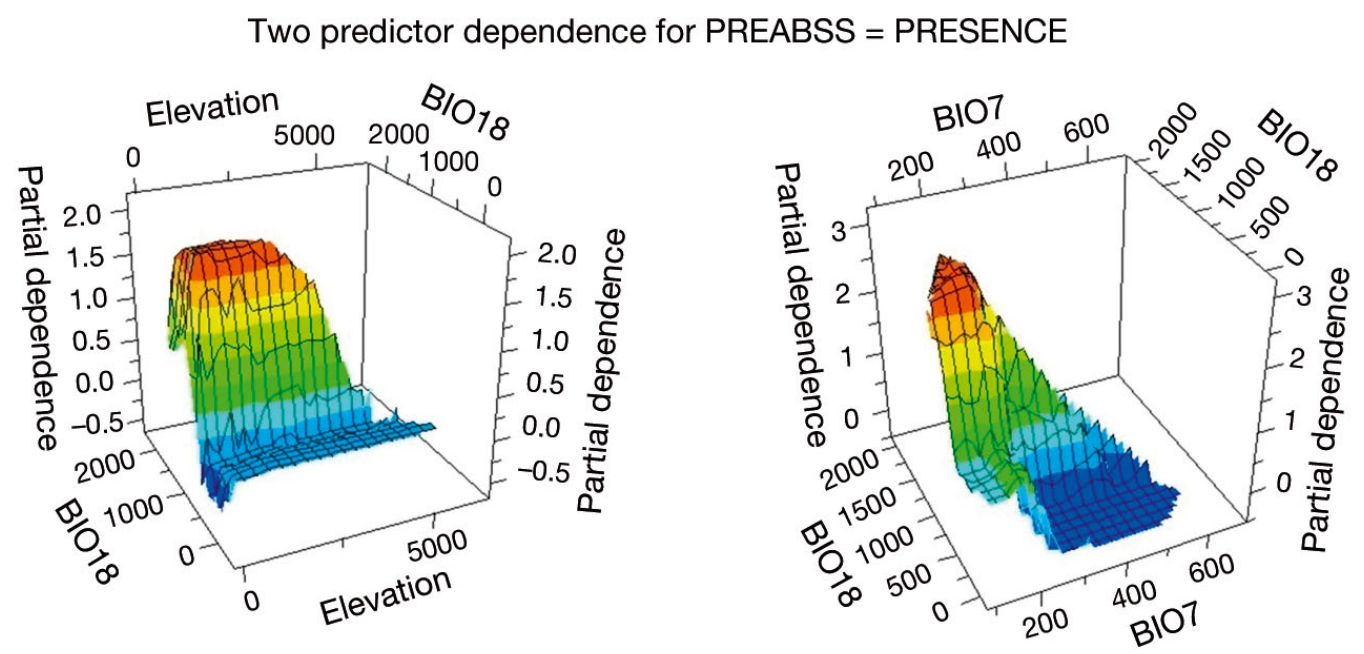

Fig. 4. Three-dimensional representation of the top predictors (a) BIO18 and elevation, and (b) BIO7 and BIO18 (see Table 1) to explain Assamese macaque occurrence. PREABSS: Presence Absence

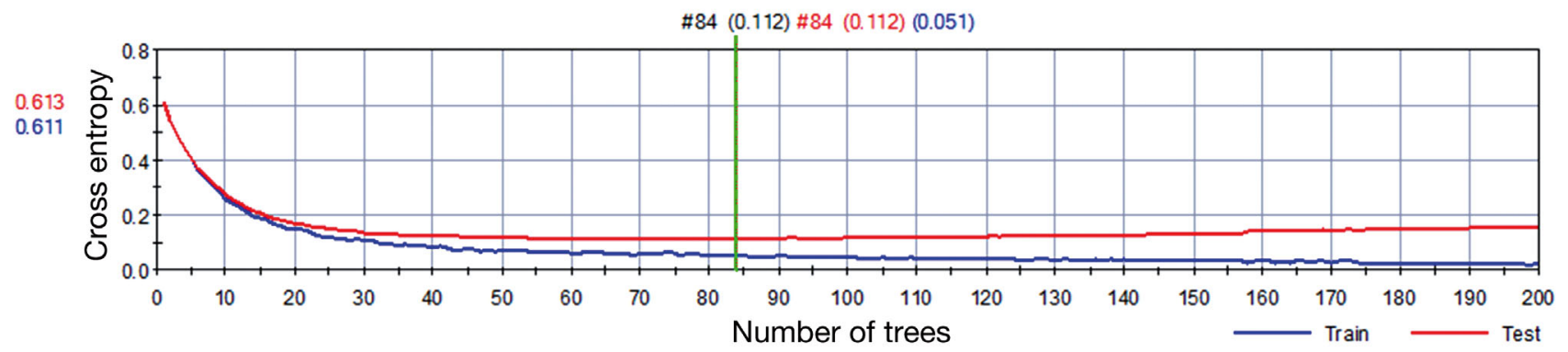

Fig. 5. Easy conversion of TreeNet model on the complex Assamese macaque dataset 


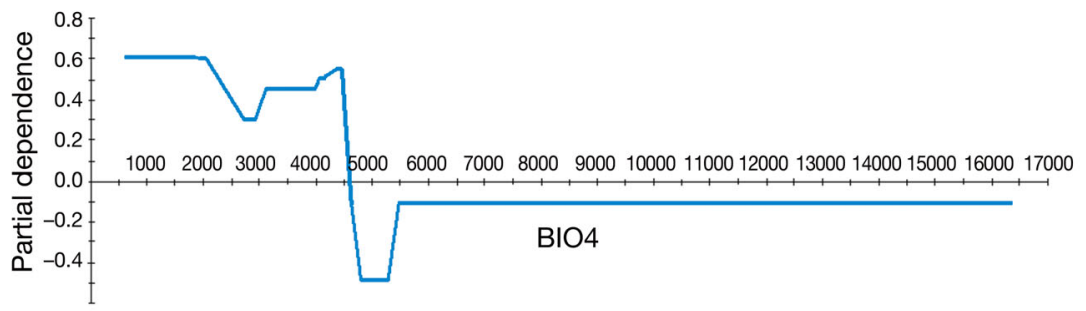

Fig. 6. Partial dependence plot of presence and pseudo-absence (random) in TreeNet for BIO4 showing a relative index of occurrence (RIO) threshold (presence) at a BIO4 of 4500 units

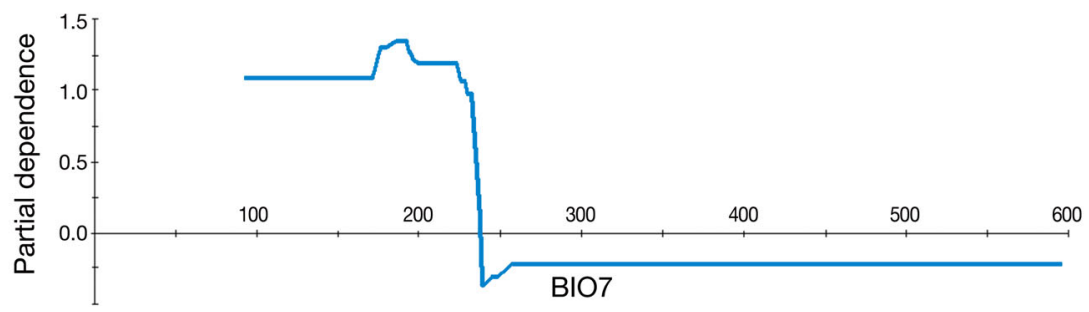

Fig. 7. Partial dependence plot of presence and pseudo-absence (random) in TreeNet for BIO7 showing a relative index of occurrence threshold (presence) of at a $\mathrm{BIO} 7$ of 240

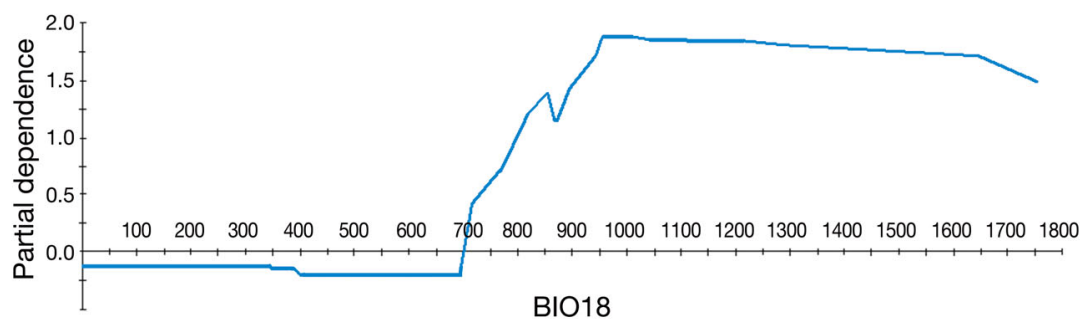

Fig. 8. Partial dependence plot of presence and pseudo-absence (random) in TreeNet for BIO18 showing a relative index of occurrence threshold for RIO (presence) at a BIO18 of 700

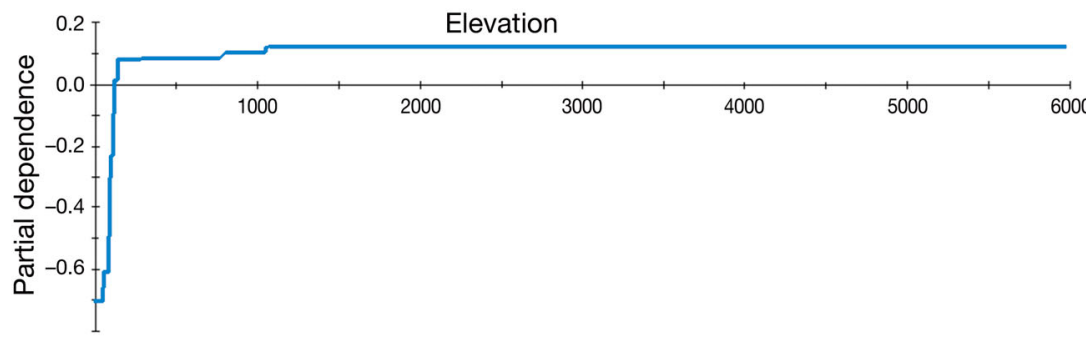

Fig. 9. Partial dependence plot of presence and pseudo-absence (random) in TreeNet for elevation showing a relative index of occurrence threshold (presence) at 200 m elevation

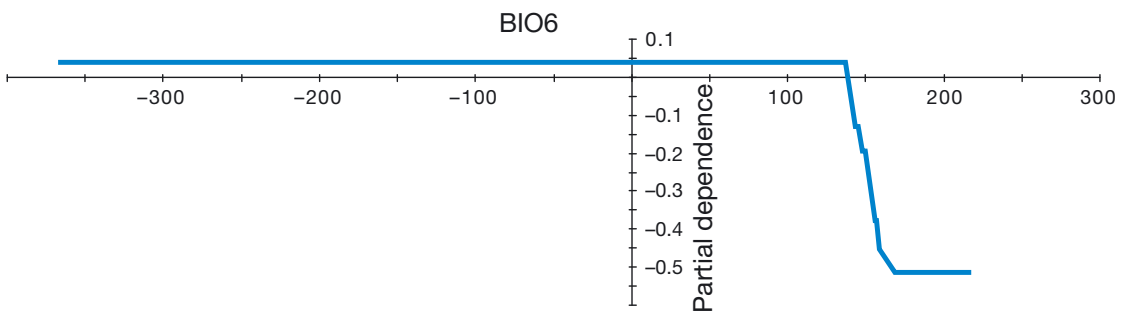

Fig. 10. Partial dependence plot of presence and pseudo-absence (random) in TreeNet for BIO6 showing a relative index of occurrence threshold (presence) at a BIO6 of 140

\section{Predicted Assamese macaque hotspots}

We have predicted here the suitable geographic areas (hotspots) for Assamese macaques using a multivariate set of bioclimatic and elevational predictors (Fig. 2). However we have not dealt with genetics, interspecific competition, predators, diseases, humaninduced survival threats, natural calamities and geographic barriers in our analysis. These predicted hot-and coldspots are completely based on the suitable climatic niche and the few known presence locations, all expressed in a quantitative fashion for further applications. Machine learning and the ensemble model were very well able to extract major signals from the complex data cube we assembled.

Our ensemble model, which we derived from averaging all models (CART, TreeNet, RandomForests and Maxent), shows that when using an expert threshold, a total area of about $534200 \mathrm{~km}^{2}$ is potential habitat for Assamese macaque in South and Southeast Asia. India has the largest suitable area $\left(141300 \mathrm{~km}^{2}\right)$, followed by Myanmar $\left(124100 \mathrm{~km}^{2}\right)$, Laos $\left(82000 \mathrm{~km}^{2}\right)$, Vietnam $\left(72000 \mathrm{~km}^{2}\right)$, China $\left(41700 \mathrm{~km}^{2}\right)$ and then Nepal $\left(34700 \mathrm{~km}^{2}\right)$ (details in Supplement 5). As expected, our results show that there are no suitable areas for Assamese macaques in Pakistan and Afghanistan. Although the ensemble model predicted a $200 \mathrm{~km}^{2}$ geographic area in Cambodia, it seems that this area is not enough to support viable macaque populations in this country. However, since this small predicted area adjoins the Laos and Vietnam regions, overall, this area could be supportive for the adjoining population of Assamese macaques. This deserves more research, because to date, Assamese macaques have not been reported from Cambodia. The predicted areas and the Assamese macaque hot- and coldspots maps are available online as Supplements 6-11. 


\section{DISCUSSION}

The data, models and their outputs produced here are the first of their kind for predicting the climate envelope distribution of Assamese macaque Macaca assamensis using an open access data-sharing concept. Our models performed well, with AUCs $>0.95$. Our models consistently selected $\mathrm{BIO} 4, \mathrm{BIO}$, BIO18, elevation and BIO6 as a multivariate 'predictor package' important for determining the macaque distribution; our results support that animals as complex as monkeys cannot be studied well with reductionistic single-predictor approaches and parsimony. These predictors we identified serve as proxies, but are the key determinants of the vegetation structure and distribution pattern for this complex tropical study area. Our models also confirmed that there are no geographically suitable areas in Afghanistan and Pakistan, possibly due to the absence there of any suitable habitat for Assamese macaque.

As typically found in such models, we used climate envelope predictions in place of forest type in our analysis, and this provided a rather strong prediction. Hence, our ecological niche models revealed only the potential geographic distribution of the Assamese macaque based on the bioclimatic and altitude variables. Nevertheless, our study provides the first ever database (see Supplements $2 \& 4$ at www.int-res.com/ articles/suppl/n036p149_supp2+4.zip), which can be further refined with additional data collected subsequently on the distribution of Assamese macaque. Socio-economic data come to mind as the next choice for insight and management. It should be noted that, when computing distribution, these models do not yet fully account for the possible interactions with other sympatric macaques, predators, diseases and dispersal (Elith et al. 2006); hence, the generated distribution map represents the potential climatic niche of the species and not the realized niche. Further research is required to develop better models in space and time which will take into consideration the realized niche and a pixel scale analysis of different niche types.

The pioneering thoughts about why species are where they are, and why they are absent, ultimately lead to the concept of comparing the environmental factors inside and outside a species' known distribution range (Hutchinson 1957 in Cushman \& Huettmann 2010). Our predictive models have identified mid-elevation moist broadleaf evergreen forest as an important habitat (which is expressed through proxies of that vegetation zone). The areas where our models predicted unsuitable habitat, for instance, are areas west of the Kaligandaki River in Nepal, a region lacking broadleaf evergreen forests (Fooden 1980, 1982, Polunin \& Stainton 1999). Temperature and precipitation are 2 of the important factors that determine the occurrence of different types of forest in the Himalayas (Polunin \& Stainton 1984). More attention should be given to the Kaligandaki River boundary zone and its features for Assamese macaque in the future, as it appears to be a major factor influencing the occurrence of the species.

This statement is further supported by our model results, as most of our models selected BIO4 (temperature seasonality), BIO7 (temperature annual range) and BIO18 (precipitation of warmest quarter) as the top climatic predictors. Fooden (1982) suggested that forest type rather than temperature determines the distribution of Assamese macaque; however, this is not based on quantitative analysis or modern methodology and does not include the latest data. In addition, vegetation is largely driven by the 'temperature niche' and thus these factors cannot really be separated from each other but come together as a multivariate package. The complete predicted absence of geographically suitable areas for the species in Pakistan and Afghanistan in our models supports this wider notion, as mid-elevation broadleaf evergreen forests are widely absent in these countries (Polunin \& Stainton 1999). Although a few troops of Assamese macaque have been recorded in forests dominated by deciduous trees and bamboo as well as in agricultural lands (Fooden 1982, Regmi \& Kandel 2008, Regmi et al. 2013), these are still situated in the immediate vicinity of broadleaf evergreen forest ecosystems with rock outcrops along rivers and streams.

Traditional biogeography theory already suggests that species do not inhabit all areas that meet their niche requirements; rather, barriers to dispersal will often restrict species to a subset of these areas (Peterson 2006, Lomolino et al. 2010).

Asia is already known for some major biogeographical barriers, e.g. Wallace Line (Lomolino et al. 2010) and several plant species in the Himalayas (Miehe \& Pendry 2016). The distribution of Indian fish shows a barrier that is explained by the Satpura hypothesis (Hora 1944, 1949). Here we add our prediction for a Kaligandaki River barrier based on the Assamese macaque (Fooden 1982 identified the Brahmaputra River in northeastern India as the zoogeographical barrier separating the 2 subspecies).

Our ecological niche models have predicted some geographically suitable areas in the Western Ghats of India for Assamese macaques, which are outside the known distribution range of the species (Boon- 
ratana et al. 2008). However, there are occurrences of 3 species of macaques in the Western Ghats rhesus macaque $M$. mulatta, bonnet macaque $M$. radiate and lion-tailed macaque $M$. silenus. In ecological niche models, some geographically suitable areas are expected to be uninhabited by the species (Peterson 2006), possibly due to biotic interactions, predators, historic mass extinction because of diseases and natural catastrophes, niche shifts and niche evolution due to climate change (over thousands and millions of years) and dispersal barriers. Such niche spaces can remain empty, or are occupied by sister taxa, for instance. Although some predicted regions (e.g. Western Ghats in India) are not used by Assamese macaques, such model predictions remain useful for determining species' ranges, analyzing their evolution and informing conservation, as ecological niche models are known to offer considerable predictive ability for understanding the distribution of a species, and possibly also a related (sister) species that shares a similar ecological niche (Peterson 2006).

Similarly, ecological niche models may not predict all the areas where species were historically present. In our models, our prediction did not capture habitat for Assamese macaque in the Sundarbans areas of Bangladesh where there are historic records of the species (Fooden 1982, Wada 2005, Kawamoto et al. 2006, Boonratana et al. 2008). The isolated Sundarbans record of M. assamensis in Bangladesh is peculiar, but apparently valid (Fooden 1982); however, the places outside of the known distribution range of M. assamensis (Boonratana et al. 2008) are usually a result of misidentification of specimens of rhesus macaque Macaca mulatta, which is superficially similar to M. assamensis (see Fooden 1982, p. 2 for details). Here, niche models and our maps can be used to provide a taxonomic quality check for the historical species data provided for such locations.

Our models have covered all the known Assamese macaque locations mentioned by Fooden (1982) from east and central Nepal through Bhutan, northeastern India (Sikkim, northern West Bengal, Nagaland, Arunachal Pradesh), northern and eastern Myanmar, southern China (Xizang, Yunnan, Guangxi), northern and western Thailand, Lao PDR and northern Vietnam. The models also predicted a few highly suitable areas in Uttarakhand in northwestern India. Interestingly, a disjunct population of Assamese macaque was recently discovered from this area (www.sanctuaryasia.com/component/content/article/ 7880-kala-bandar-the-mystery-macaque-of-uttara khand.html), well beyond the western distribution (i.e. Kaligandaki River in Nepal) of the macaque. It should be noted here that we were, however, unable to obtain presence location data for the Assamese macaque from Uttarakhand. Similarly, the sympatric and sister macaque species - the white-cheeked macaque $M$. leucogenys - has recently been described from our predicted highly suitable areas in Southeast China (Li et al. 2015). We think this exemplifies the power, elegance and applicability of our methods and models for discovering new populations of the known species and new sympatric species as well as for conservation.

In Bhutan, broadleaf forests and Assamese macaques are confined up to $2900 \mathrm{~m}$ above sea level throughout the country (Wangchuk et al. 2004). Our model has predicted the potential habitats of Assamese macaque in these areas (along highways between Thimpu to Phuntsholing, Punakha, Trongsa, Zhemgang and Trashigang) where the macaques have frequently been reported (Wangchuk et al. 2004). Assamese macaques are sympatric with golden langur Trachypithecus geei in Zhemgang and Trongsa in central Bhutan, capped langur Trachypithecus pileatus in eastern Bhutan and hanuman langur Semnopithecus entellus in western Bhutan (Wangchuk et al. 2004). Thus, it seems that conserving broadleaf forest in Bhutan and elsewhere would help protect the Assamese macaques and other sympatric primates.

The isolated distribution of the Assamese macaque would appear to make it unlikely that a viable population of the species can be maintained in Nepal in the long term (Wada 2005), and this may also be the case in other areas of their distribution range. There have been only a few studies to determine the minimal viable population size necessary for the conservation not only of Assamese monkeys, but also of Macaca in general (Wada 2005). A species' viability must be measured by evaluating population dynamics and environmental effects (Fa \& Lind 1996, Nielsen et al. 2008). Considering these facts, we suggest as next research goals using the data we provided for carrying out dispersal and spatial population viability assessments (Nielsen et al. 2008) based on future distributions and habitat shift assessments of Assamese monkeys under scenarios of future climate change, increased human consumption, habitat transitions and human population. This should follow a threshold analysis of minimum population and habitat sizes for direct management of such species, all of which are currently lacking. We emphasize here that information on these subjects is sparse and difficult to find. 


\section{CONCLUSIONS}

Our data, model and findings present the bestavailable distribution and barrier information for Assamese macaque Macaca assamensis. This study further offers a new research template for primates and has direct relevance for conservation. Primatologists and conservation managers could, for instance, plan future surveys of macaques in the highly suitable areas where data are not shared or available, and where surveys have never taken place; new macaque populations might be discovered in such potential sites. The model outcomes can also be applied to identify fragmented habitat, to reduce anthropogenic pressure on suitable habitat, and for effective habitat management and restoration, e.g. for translocation of macaques to suitable sites and for managing and mitigating human-macaque conflict, all of which are major challenges for wildlife managers throughout South and Southeast Asia.

Acknowledgements. G.R.R. was supported by an MSc Primate Conservation Habitat Country Scholarship from Oxford Brookes University, Oxford, UK. Funding support for the fieldwork in Nepal to G.R.R. was received from The Rufford Foundation, UK, the Ocean Park Conservation Foundation, Hong Kong, the Primate Society of Great Britain, UK, and the American Society of Primatologists, USA; Idea Wild, USA, granted field equipment. The Department of National Parks and Wildlife Conservation and the Department of Forests/Government of Nepal are thanked for granting permission to collect the field data in Nepal. The authors also thank the EWHALE lab of University of Alaska Fairbanks (UAF), USA and its students for their technical support and infrastructure for this work. GMBA, ICIMOD and GBIF are kindly thanked for providing their public open access biodiversity data efforts and for a sabbatical stay by F.H. F.H. acknowledges the great work by D. Carlson pushing for Open Access, as well as support by D. Steinberg and his team from Salford Systems Ltd; L. Strecker, I. Presse, B. Bluhm and S. Linke are kindly acknowledged for earlier help. Our team also thanks Yadav Ghimirey, Dr. Nabajit Das, Prof. Julia Ostner and Prof. Suchinda Malaivijitnond for providing their presence-only data for Assamese macaque. This is EWHALE lab publication \# 166.

\section{LITERATURE CITED}

Boonratana R, Chalise M, Das J, Htun S, Timmins RJ (2008) Macaca assamensis. Boonratana R, Chalise M, Das J, Htun S, Timmins RJ (2008) Macaca assamensis. The IUCN Red List of Threatened Species 2008: e.T12549A3354977. http://dx.doi.org/10.2305/IUCN.UK.2008.RLTS.T12549A 3354977.en (accessed 22 Sep 2012)

Breiman L (2001) Statistical modeling: the two cultures. Stat Sci 16:199-215

Chakraborty D, Ramakrishnan U, Panor J, Mishra C, Sinha A (2007) Phylogenetic relationships and morpho- metric affinities of the Arunachal macaque Macaca munzala, a newly described primate from Arunachal Pradesh, northeastern India. Mol Phylogenet Evol 44: 838-849

Chalise MK (1999) Report on the Assamese monkeys (Macaca assamensis) of Nepal. Asian Primates 7:7-11

Chalise MK, Ghimire MK (1998) Non-human primate census in different parts of Nepal. Nat Hist Soc Nepal Bull 8: $11-15$

Coudrat CN, Nekaris K (2013) Modelling niche differentiation of co-existing, elusive and morphologically similar species: a case study of four macaque species in NakaiNam Theun National Protected Area, Laos. Animals (Basel) 3:45-62

Cushman S, Huettmann F (2010) Spatial complexity, informatics and wildlife conservation. Springer, Tokyo

Drew CA, Wiersma YF, Huettmann F (eds) (2011) Predictive species and habitat modelling in landscape ecology, 1st edn. Springer, Tokyo

*Elith J, Graham H, Anderson CP, Dudík R and others (2006) Novel methods improve prediction of species' distributions from occurrence data. Ecography 29:129-151

Fa JE, Lind R (1996) Population management and viability of the Gibraltar Barbary macaques. In: Fa JE, Lindberg DG (eds) Evolution and ecology of macaques' societies. Cambridge University Press, London, p 235-262

Fooden J (1980) Classification and distribution of living macaques (Macaca Lacepede, 1799). In: Lindburg DG (ed.) The macaques: studies in ecology, behavior and evolution. Van Nostrand Reinhold Co., New York, NY, p 1-9

Fooden J (1982) Taxonomy and evolution of the Sinica group of macaques: species and subspecies accounts of Macaca assamensis. Fieldiana Zoology New Series No. 10. p 1-52

Guisan A, Broennimann O, Engler R, Vust M, Yoccoz NG, Lehmann A, Zimmermann N (2006) Using niche-based models to improve the sampling of rare species. Conserv Biol 20:501-511

* Herrick KA, Huettmann F, Lindgren MA (2013) A global model of avian influenza prediction in wild birds: the importance of northern regions. Vet Res 44:42

*Hijmans RJ, Cameron SE, Parra JL, Jones PG, Jarvis A (2005) Very high resolution interpolated climate surfaces for global land areas. Int J Climatol 25:1965-1978

Hora SL (1944) On the Malayan affinities of the freshwater fish fauna of peninsular India, and its bearing on the probable age of the Garo-Rajmahal gap. Proc Natl Inst Sci India 10:423-439

Hora SL (1949) Satpura hypothesis of the distribution of the Malayan fauna and flora to peninsular India. Proc Natl Inst Sci India 15:309-314

Huettmann F (ed) (2012) Protection of the three poles. Springer, Tokyo

*Huettmann F, Diamond AW (2001) Seabird colony locations and environmental determination of seabird distribution: a spatially explicit seabird breeding model in the Northwest Atlantic. Ecol Modell 141:261-298

* Hutchinson GE (1957) Concluding remarks. Cold Spring Harb Symp Quant Biol 22:415-427

Jochum K, Huettmann F (2010) Spatial information management in wildlife ecology: adding spatially explicit behavior data to the equation? In: Cushman S, Huettmann F (eds) Spatial complexity, informatics and wildlife conservation. Springer, Tokyo, p 175-192 
Kandel K, Huettmann F, Suwal MK, Regmi GR and others (2015) Rapid multi-nation distribution assessment of a charismatic conservation species using open access ensemble model GIS predictions: red panda (Ailurus fulgens) in the Hindu-Kush Himalaya region. Biol Conserv 181:150-161

Kawamoto Y, Aimi M, Wangchuk T (2006) Distribution of Assamese macaques (Macaca assamensis) in the Inner Himalayan region of Bhutan and their mtDNA diversity. Primates 47:388-392

Li C, Zhao C, Fan PF (2015) White-cheeked macaque (Macaca leucogenys): a new macaque species from Modog, southeastern Tibet. Am J Primatol 77:753-766

Lomolino MV, Riddle BR, Whittaker RJ, Brown JH (2010) Biogeography, 4th edn. Sinauer, New York, NY

Manly B, McDonald LI, Thomas DL, McDonald TL, Erickson WP (2002) Resource selection by animals: statistical design and analysis for field studies, 2nd edn. Kluwer Academic, New York, NY

Miehe G, Pendry C (2016) Nepal: an introduction to the natural history, ecology, and human environment of the Himalayas. Royal Botanical Garden, Edinburgh

Molur S, Brandon-Jones D, Dittus W, Eudey A and others (2002) Status of South Asian primates: conservation assessment and management plan (CAMP). Zoo Outreach Organisation/CBSG-South Asia, Coimbatore. http:// zooreach.org/downloads/ZOO_CAMP_PHVA_reports/ $2003 \% 20$ Primate \%20Report.pdf

Moyes CL, Shearer FM, Huang Z, Wiebe A and others (2016) Predicting the geographical distributions of the macaque hosts and mosquito vectors of Plasmodium knowlesi malaria in forested and non-forested areas. Parasit Vectors 9:242

Nemitz D, Huettmann F, Spehn E, Dickoré WB (2012) Mining the Himalayan uplands plant database for a conservation baseline using the public GMBA webportal. In: Huettmann F (ed) Protection of the three poles. Springer, Tokyo, p 135-158

Nielsen SE, Stenhouse GB, Beyer HL, Huettmann F, Boyce MS (2008) Can natural disturbance-based forestry rescue a declining population of grizzly bears? Biol Conserv 141:2193-2207

Peterson AT (2006) Uses and requirements of ecological niche models and related distribution models. Biodivers Inform 3:59-72

Editorial responsibility: Nils Bunnefeld, Stirling, UK
Phillips SJ, Anderson RP, Schapire RE (2006) Maximum entropy modeling of species geographic distributions. Ecol Modell 190:231-259

Polunin O, Stainton A (1984) Flowers of the Himalaya. Oxford University Press, New Delhi

Polunin O, Stainton A (1999) Concise flowers of the Himalaya. Oxford University Press, New Delhi

Popp J, Neubauer D, Paciulli L, Huettmann F (2007) Using TreeNet for identifying management thresholds of mantled howling monkeys' habitat preferences on Ometepe Island, Nicaragua, on a tree and home range scale. J Med Biol Sci 1:1-14

Regmi GR, Kandel K (2008) Population status, threats and conservation measures of Assamese macaque (Macaca assamensis) in Langtang National Park, Nepal. Primate Eye 96:19-20

Regmi GR, Nekaris KAI, Kandel K, Nijman V (2013) Cropraiding macaques: predictions, patterns and perceptions from Langtang National Park, Nepal. Endang Species Res 20:217-226

Sharma N, Madhusudan MD, Sarkar P, Bawri M, Sinha A (2012) Trends in extinction and persistence of diurnal primates in the fragmented lowland rainforests of the Upper Brahmaputra Valley, north-eastern India. Oryx 46:308-311

Sinha A, Datta A, Madhusudan MD, Mishra C (2005) Macaca munzala: a new species from western Arunachal Pradesh, northeastern India. Int J Primatol 26:977-989

* Thorn J, Smith D, Nijman VI, Nekaris KA (2009) Ecological niche modeling as a technique for assessing threats and setting conservation priorities for Asian slow lorises (Primtes: Nycticebus). Divers Distrib 15:289-298

* Vidal-García F, Serio-Silva JC (2011) Potential distribution of Mexican primates: modeling the ecological niche with the maximum entropy algorithm. Primates 52:261-270

Wada K (2005) The distribution pattern of rhesus and Assamese monkeys in Nepal. Primates 46:115-119

Wangchuk T, Thinley $\mathrm{P}$, Tshering $\mathrm{K}$, Tshering $\mathrm{C}$, Yonten D, Pema B, Wangchuk S (2004) A field guide to the mammals of Bhutan. Department of Forestry, Ministry of Agriculture, Royal Government of Bhutan, Thimphu

* Yang LL, Huettmann F, Brown JL, Liu SQ, Wang WX, Yang JY, Hu DF (2015) Fecal glucocorticoid metabolite relates to social rank in Sichuan snub-nosed monkeys. Ital J Zool $83: 15-25$

Submitted: June 28, 2017; Accepted: March 14, 2018

Proofs received from author(s): June 5, 2018 